\title{
EL CONTRATO DE CONCESIÓN DE OBRA PÚBLICA: NOVEDADES DE SU RÉGIMEN JURÍDICO
}

\author{
JUAN MARTÍNEZ CALVO \\ Deloitte Abogados \\ jmartinezcalvo@deloitte.es
}

\begin{abstract}
Cómo citar/Citation
Martínez Calvo, J. (2018).

El contrato de concesión de obra pública: novedades de su régimen jurídico.

Revista de Administración Pública, 206, 319-356.

doi: https://doi.org/10.18042/cepc/rap.206.11
\end{abstract}

\section{Resumen}

Los contratos concesionales han sido aquellos cuyo régimen jurídico se ha modificado más profundamente en la nueva Ley 9/2017 de Contratos del Sector Público. Esto deriva de la necesidad de transponer la Directiva Comunitaria 2014/23/UE relativa a la adjudicación de los contratos de concesión, pero también del impacto que sobre muchos contratos concesionales ha tenido la crisis económica («caso radiales» muy destacadamente, pero también otros muchos). El presente artículo analiza las novedades de la ley en relación con el contrato de concesión de obra, contextualizando dichas novedades en la problemática práctica que habitualmente se genera en la estructuración, licitación, financiación y gestión en el largo plazo de este tipo de contratos.

\section{Palabras clave}

Concesión de obra pública; contratos públicos; riesgo operacional; ciclo de vida del producto; reequilibrio.

\section{Abstract}

The concession contracts have been those whose legal regime has been modified more deeply in the new Law 9/2017 on Public Sector Contracts. This derives 
from the transposition process of the EU Directive 2014/23 / EU on the awarding of concession contracts, but also from the impact that the economic crisis has generated on many concession contracts («radial cases» very prominently, but also other many). This article analyzes the novelties of the Law in relation to the work concession contract, contextualizing said novelties in the practical problems that are usually discussed in the structuring, bidding, financing and long-term management of this type of contracts.

\section{Keywords}

Public works concession; public contracts; operational risk; product life cycle; rebalancing. 


\section{SUMARIO}

I. NOVEDADES SOBRE SU NATURALEZA JURÍDICA: EL REQUISITO DE TRANSFERENCIA DEL RIESGO OPERACIONAL EN LA EXPLOTACIÓN DE LA OBRA: 1. La nueva definición del contrato de concesión de obras. 2. Requisitos para la existencia de «riesgo operacional» en los contratos de concesión de obras. 3. Concesión de obras, riesgo operacional y déficit público: interrelación con el Sistema Europeo de Cuentas. II. NOVEDADES EN EL RÉGIMEN JURÍDICO DE LA PREPARACIÓN, LICITACIÓN Y ADJUDICACIÓN DEL CONTRATO DE CONCESIÓN DE OBRAS: 1.El estudio de viabilidad del contrato. 2. Valor estimado del contrato. 3. Plazo de presentación de ofertas. 4. Propuestas de iniciativa privada. 5. Acreditación de solvencia. 6. Lotes. 7. Garantías. 8. Criterios de adjudicación: el ciclo de vida del producto. III. NOVEDADES EN EL RÉGIMEN JURÍDICO-MATERIAL DEL CONTRATO: 1. Plazo del contrato. 2. Cesión del contrato y venta de participaciones. 3. Matriz de riesgos. 4. Modificación del contrato. 5. La retribución como prestación patrimonial de carácter público. 6. Revisión de precios. 7. Reequilibrio económico financiero del contrato. 8. Financiación privada de concesiones. 9. Indemnización en caso de resolución anticipada del contrato.

\section{NOVEDADES SOBRE SU NATURALEZA JURÍDICA: EL REQUISITO DE TRANSFERENCIA DEL RIESGO OPERACIONAL EN LA EXPLOTACIÓN DE LA OBRA}

\section{LA NUEVA DEFINICIÓN DEL CONTRATO DE CONCESIÓN DE OBRAS'}

El art. 14 de la nueva Ley 9/2017, de 8 de noviembre, de Contratos del Sector Público (LCSP) define el contrato de concesión de obra, reemplazando

1 El presente artículo se plantea como objetivo analizar, básicamente, las novedades de la nueva ley. Para una visión global del vigente régimen jurídico del contrato de concesión de obra pública puede verse Jesús Jiménez López (2018), «El contrato de concesión de obras», en E. Gamero Casado e I. Gallego Córcoles, Tratado de Contratos del Sector Público (págs. 2506-2570), Valencia, Tirant lo Blanch. En relación con las novedades formales y las remisiones internas del propio texto de la ley, se hace un detallado análisis en J. J. Lavilla Rubira (2018), «Régimen jurídico de la concesión de obras", en J. M. Gimeno Feliú (dir.), Estudio sistemático de la Ley de contratos del sector público, Thomson Reuters-Aranzadi, págs. 1416-1421. 
al antiguo art. 7 del TRLCSP de 2011. De entrada, plantea una modificación terminológica, pues la denominación del contrato pasa a ser "contrato de concesión de obras» frente al anterior "contrato de concesión de obras públicas».

De acuerdo con el nuevo art. 14,1:

[...] la concesión de obras es un contrato que tiene por objeto la realización por el concesionario de algunas de las prestaciones a que se refiere el artículo anterior, incluidas las de restauración y reparación de construcciones existentes, así como la conservación y mantenimiento de los elementos construidos, y en el que la contraprestación a favor de aquél consiste, o bien únicamente en el derecho a explotar la obra en el sentido del apartado cuarto siguiente, o bien en dicho derecho acompañado del de percibir un precio.

Hasta aquí no hay ninguna novedad más allá de la terminológica citada. Los apdos. 2 y 3 del art. 14, describen, sin introducir tampoco ninguna novedad relevante ${ }^{2}$ respecto del texto de 2007 , la mención a que el contrato de obra pública (i) puede incluir no solo obras de nueva construcción sino también reformas o reposiciones y (ii) puede prever obligaciones en relación con obras accesorias a la principal.

La gran novedad conceptual es la que aparece en el apartado cuarto de este art. 14 que introduce el concepto de «riesgo operacional» como nuevo concepto clave para identificar el contrato de concesión de obra:

4. El derecho de explotación de las obras, a que se refiere el apartado primero de este artículo, deberá implicar la transferencia al concesionario de un riesgo operacional en la explotación de dichas obras abarcando el riesgo de demanda o el de suministro, o ambos. Se entiende por riesgo de demanda el que se debe a la demanda real de las obras o servicios objeto del contrato y riesgo de suministro el relativo al suministro de las obras o servicios objeto del contrato, en particular el riesgo de que la prestación de los servicios no se ajuste a la demanda.

Se considerará que el concesionario asume un riesgo operacional cuando no esté garantizado que, en las condiciones normales de funcionamiento, el mismo vaya a recuperar las inversiones realizadas ni a cubrir los costes en que hubiera incurrido como consecuencia de la explotación de las obras que sean objeto de concesión. La parte de los riesgos transferidos al concesionario debe suponer una exposición real a las incertidumbres del mercado que implique que cualquier pérdida potencial estimada en que incurra el concesionario no es meramente nominal o desdeñable.

2 La única novedad es la referencia reiterada en el 14,2 a la necesidad de que la obra pública se ejecute en todo caso a riesgo y ventura del contratista, lo que se desarrolla ampliamente en el 14,4. 
Antes de entrar en el análisis de la nueva definición de la «explotación de las obras» y el «riesgo operacional» del art. 14,4 deben hacerse dos consideraciones previas:

a) La nueva definición de lo que es el derecho a explotar la obra es una traslación literal del texto de la Directiva de Concesiones. En este caso, como en otros muchos de la nueva LCSP, el legislador ha utilizado poco la posibilidad de desarrollar y concretar, al transponer, los conceptos de la Directiva. Esto, en mi opinión, genera problemas y es un error. En el equilibrio entre no recibir cuestionamientos por no hacer una transposición ajustada a la Directiva y prescindir de ajustar la Directiva a los conceptos ya asentados de nuestra tradición jurídica de contratación pública, la decisión ha sido la primera de forma extremosa y criticable. Una Directiva comunitaria no es un reglamento precisamente porque debe adaptarse al ordenamiento interno. No se trata solo de que el Estado miembro pueda desarrollar y matizar concepto, es que la lógica del sistema lo exige. Por ese motivo los textos de Directivas y Reglamentos no son normalmente iguales en su estructura lingüística y obligacional ${ }^{3}$.

b) El requisito de explotar la obra ya aparecía en los textos de las leyes de contratos públicos de 2003 y $2007^{4}$ pero, al no existir un desarrollo legal del concepto lo cierto es que los problemas conceptuales que planteó fueron mucho menores que los que el nuevo 14,4 genera. Esto sin perjuicio de que el requisito de la «explotación de las obras» dio lugar a dudas prácticas y atención por parte de los órganos consultivos y tribu-

3 Suscribo a este respecto en su totalidad la crítica que hace J. Santamaría Pastor (2016) en «Contratos Públicos y Derecho de la Unión», Revista de Administración Pública, 200, págs. 83-102, al enfoque hagiográfico hacia la regulación comunitaria en materia de contratación pública que parece instalado en nuestra doctrina. La transposición que se ha hecho de la Directiva de Concesiones es fiel seguidora de este enfoque doctrinal. Es destacable, al menos en materia de concesiones, la casi nula crítica a las sentencias del TSJUE en la materia concesional que, en mi opinión, están en muchas ocasiones manifiestamente desenfocadas por el «Problema Alemán» que explica A. Huergo Lora (2000) en «La nueva regulación de los contratos públicos en Alemania. Reflexiones desde el derecho español», en El Derecho Administrativo en el umbral del siglo XXI. Homenaje al Prof. Dr. don Ramón Martín Mateo, vol. II, págs. 1841-1878, Valencia: Tirant lo Blanch.

4 Esto es importante recordarlo, en nuestra legislación de contratación pública siempre fue necesario que los contratos de concesión de obras implicaran «explotación de la obra» para que pudieran ser calificados como tal y diferenciarse de los de obras. 
nales 5 . En todo caso cualquier análisis de lo que en la normativa anterior significaba «explotar la obra» ya no sirve como referencia, pues la Directiva y la Ley han desarrollado el concepto de tal manera que no es posible entender que sean asimilables los requisitos de explotación previos a la entrada en vigor de la Ley de 2017.

5 Sobre esta discusión de lo que implicaba el riesgo de explotación en el contexto de las leyes de 2003 y 2007 pueden consultarse los informes 61/03, de 12 de marzo de 2004, y 70/04, de 11 de marzo de 2005, de la Junta Consultiva de contratación administrativa. En el informe 61/03 se afirma que no es posible jurídicamente la utilización del contrato de concesión de obra pública para licitar la construcción y explotación de un edificio para albergar los servicios centrales de la Universidad de Burgos. El argumento que da la Junta Consultiva es que tal inmueble no parecía susceptible de explotación económica. Lo cierto, sin embargo, es que en este informe no se profundiza en el modo de pago, transmisión de riesgos, etc., que se proyectaban por parte de la Universidad de Burgos, que es lo que, en mi opinión, permite calificar un inmueble como susceptible de explotación económica o no. En el informe 70/04, de 11 de marzo de 2005, la Junta Consultiva vuelve a ratificarse en su criterio en relación con la construcción de un edificio de usos sociales y culturales. En este informe se detalla por el Ayuntamiento que solicita la consulta el modelo de retribución que se prevé, señalándose que será una cantidad fija a pagar por el propio Ayuntamiento. La Junta Consultiva concluye, en mi opinión con toda corrección, que tampoco en este caso existe un contrato de concesión de obra pública, pues está claro que no hay riesgo. Ahora bien, el informe no excluyó en absoluto la posibilidad de que con otro sistema de pago sí pudiera haber una concesión de obra pública sobre un edificio con tales usos.

Sobre el particular véase V. Horcajuelo Rivera (2016), «El elemento de transmisión de riesgo en los contratos de gestión de servicio público», en M. A. Recuerda Girela (dir.), Problemas Prácticos y Actualidad del Derecho Administrativo, Anuario de Derecho Administrativo, 2016 (págs. 853 y ss.), Madrid: Civitas-Thomson Reuters. Como explica el autor, toda la jurisprudencia del TSJUE sobre el concepto de riesgo de explotación (Sentencias Eurawasser, Parking Brixen, Privater Rettungsdienst, etc.) debe considerarse con gran cautela para valorar el significado en la ley espańola del concepto de riesgo de explotación y de riesgo operacional. Dichas sentencias no están dictadas al amparo del texto de la Directiva de Concesiones y, sobre todo, giran en torno a la problemática continua de la no licitación en determinadas jurisdicciones (sobre todo Alemania) de los contratos concesionales al amparo de su no armonización. Ese es un problema que en España nunca se ha planteado y la vis atractiva desarrollada por el TSJUE en dicha jurisprudencia hacia el contrato de servicios, "forzando" la exigencia de traslación de riesgo, no sirve para explicar entre nosotros correctamente el concepto de riesgo operacional (o de explotación) de nuestra LCSP. 


\section{REQUISITOS PARA LA EXISTENCIA DE «RIESGO OPERACIONAL»EN LOS CONTRATOS DE CONCESIÓN DE OBRAS ${ }^{6}$}

Entramos a continuación a analizar el confuso art. 14,4 de la nueva LCSP que define lo que significa el «riesgo de explotación».

En primer lugar, señala el art. 14,4 que: «El derecho de explotación de las obras [...] deberá implicar la transferencia al concesionario de un riesgo operacional en la explotación de dichas obras [...]».

La ley empieza a ser confusa incluso al establecer la relación entre riesgo de explotación y riesgo operacional. ¿¿Son cosas distintas o es lo mismo? Mi opinión es que, en el contexto de un contrato de concesión de obras, son conceptos análogos, pero aún esto no es del todo claro, pues la ley no explica el motivo por el que se utilizan dos términos diferentes. ¿Podría interpretarse que existen derechos de explotación de las obras que no trasladan el riesgo operacional? Parece más bien que la ley usa los términos como sinónimos, es decir, el necesario derecho de explotación de la obra implica en todo caso la translación del riesgo operacional. Defender lo contrario implicaría que existieran, por ejemplo, contratos de obra o servicios que trasladaran el derecho de explotación, pero no riesgo operacional, lo cual no tendría efecto práctico alguno para esos contratos. En resumen, la interpretación más lógica es la de que si no hay riesgo operacional no hay derecho de explotación, pero, por eso mismo, la redacción de la ley es muy mejorable, pues la introducción del nuevo concepto no parece que tenga utilidad alguna (más allá de escribir una norma que copie literalmente la Directiva $)^{7}$.

Dicho riesgo operacional en la explotación debe abarcar el riesgo de demanda o el de suministro o ambos. Se trata por tanto de «riesgos» cuya asignación al contratista son alternativos, no acumulativos. Es decir, con la

6 Dado que en el contrato de concesión de servicios la ley hace una remisión completa para determinar si existe riesgo operacional al art. 14,4, la exposición de este apartado es aplicable íntegramente a los contratos de concesión de servicios.

7 Sobre el concepto de riesgo operacional puede verse: D. Sanz Pérez y M. Reverter Baquer (2016), «La Directiva de Concesiones: Especial atención al riesgo operacional y su aplicación práctica en nuestro ordenamiento», en M. A. Recuerda Girela (coord.), Problemas prácticos y actualidad del Derecho Administrativo. Anuario 2016, Madrid: Civitas-Thomson Reuters. A. Huergo Lora (2017), «El riesgo operacional en la nueva Ley de Contratos del Sector Público», Documentación Administrativa, 4 (nueva época), págs. 31-51. También A. Román Márquez (2017), «El riesgo en las concesiones de obras y servicios públicos: orígenes, evolución y situación actual en el ordenamiento jurídico comunitario", Revista Española de Derecho Administrativo, 182, págs. 445-481. 
transferencia de uno de los dos, basta para que exista riesgo operacional en la explotación. A continuación, se desarrolla el significado de cada uno de estos «riesgos»:

- El riesgo de demanda se señala que es el que «se debe a la demanda real de las obras o servicios objeto del contrato». Ya la utilización del término definido en la definición complica las cosas, pero es que se utiliza el adjetivo «real» para la demanda. ¿Cabe una demanda simulada o ideal que, sin embargo, no respondería a los requerimientos de translación del riesgo operacional? No parece plausible. La interpretación más razonable parece que sería la de que se refiere a que hay terceros que usan la obra y el pago al concesionario depende de dicho pago. El adjetivo "real» plantea, sin embargo, más dudas sobre todo en relación con estructuras de pago de los denominados "peajes en la sombra», que son aquellos en los que la Administración paga al concesionario cada vez que un ciudadano hace uso de la obra pública (típicamente se ha usado en contratos de concesión de obra pública de carreteras de uso gratuito en los cuales el concesionario cobra por número de vehículos que la transitan). No se trata de una interpretación descabellada, pero en nuestra opinión debe descartarse, porque si así fuera lo razonable sería una exclusión explícita por la ley de esas estructuras de pago, lo que la ley no hace. La conclusión debe ser que el adjetivo «real» en este artículo de la ley es un recurso lingüístico para remarcar el hecho de que el riesgo debe ser de uso y no cabría un riesgo de demanda construido conceptualmente sobre criterios como contingentes teóricos o similares ${ }^{8}$. Esta interpretación se confirma por el literal del art. 267, 4 de la propia LCSP, que establece que «la retribución por la utilización de la obra podrá ser abonada por la Administración teniendo en cuenta [...] su utilización por los usuarios».

- El riesgo de suministro se define como «el relativo al suministro de las obras o servicios objeto del contrato, en particular el riesgo de que la prestación de los servicios no se ajuste a la demanda». En este caso es

8 Por ejemplo, sería discutible que existiera riesgo operacional basado en la demanda en un contrato en el que el pago que debe hacer la Administración tuviera en cuenta el número de vecinos de un barrio en el que se debe construir una obra pública (un polideportivo, por ejemplo) independientemente del uso efectivo del mismo. De la misma manera, un pago capitativo por ciudadano inscrito en un área de salud al explotador de un hospital concesionado, modelo de concesión existente entre nosotros, quizás con la nueva ley — sin más ajustes—, podría discutirse como una efectiva traslación de riesgo operacional basado en demanda si no se valora en absoluto el uso efectivo de las instalaciones hospitalarias por los pacientes. 
todavía más complejo dar una explicación racional de lo que se quiere significar en la ley, porque, aunque a priori debe tratarse de un riesgo diferente del de demanda, la definición se refiere a que la prestación de los servicios no se ajuste a la «demanda». ¿A qué demanda? ¿Por qué solo los servicios y no la obra en su complitud? Se entendería mejor la definición si se refiriera al ajuste a los requerimientos funcionales de la obra, pero no a la demanda. La interpretación razonable de qué es riesgo de suministro debe reconstruirse, pues la ley no es clara en su tenor literal. En nuestra opinión esta reconstrucción debe hacerse sobre el concepto de riesgo de ajuste de las funcionalidades que el propio pliego ha requerido para la la obra.

Esta interpretación es consistente con el, ya citado, art. 267 (retribución de las obras) cuando seńala en su punto 4:

La retribución de la obra podrá ser abonada por la Administración teniendo en cuenta el grado de disponibilidad ofrecido por el concesionario y/o utilización por los usuarios, en la forma prevista en el pliego de cláusulas administrativas particulares. En el caso de que la retribución se efectuase mediante pagos por disponibilidad deberá preverse en los pliegos de cláusulas administrativas particulares la inclusión de índices de corrección automáticos por nivel de disponibilidad independientes de las posibles penalidades en que pueda incurrir el concesionario en la prestación del servicio.

Me explico a continuación; si es posible legalmente un pago vinculado a la disponibilidad de la obra, es decir la determinación de una cifra que se matiza mediante la inclusión de índices en corrección automáticos por nivel de disponibilidad, es obvio que el riesgo de suministro puede cubrirse en un escenario de pagos por disponibilidad y, por tanto, sin referencia explícita a la demanda entendida como utilización mayor o menor por parte del usuario.

Es decir, en mi opinión es perfectamente posible un contrato de concesión de obras que no traslade ningún tipo de riesgo de demanda al contratista. El art. 14,4 no termina aquí en la definición de qué es riesgo operacional. Lo que sigue genera aún más dudas:

Se considerará que el concesionario asume un riesgo operacional cuando no esté garantizado que, en las condiciones normales de funcionamiento, el mismo vaya a recuperar las inversiones realizadas ni a cubrir los costes en que hubiera incurrido como consecuencia de la explotación de las obras que sean objeto de concesión. 
La parte de los riesgos transferidos al concesionario debe suponer una exposición real a las incertidumbres del mercado que implique que cualquier pérdida potencial estimada en que incurra el concesionario no es meramente nominal o desdeńable.

La primera parte de la definición es quizás la que mejor explica o describe qué debe ser el riesgo operacional en un contrato de concesión. La clave son las inversiones realizadas por el concesionario. En el resto de contratos típicos regulados en la LCSP por definición el cobro se realiza de forma razonablemente acompasada a la inversión: en obras por certificación de avance de obra y en suministros o servicios normalmente por avance o a la entrega del bien o servicio. Es decir, en puridad no hay inversión por el contratista. En la concesión de obra por definición sí hay esa inversión, de manera que este requerimiento de que dicha inversión no está asegurado que se vaya a recuperar es, indudablemente, la parte de la compleja definición que la ley hace del contrato de concesión de obra más valiosa y clarificadora.

El último inciso del art. 14,4 y la mención a la exposición real a las incertidumbres del mercado no parece que aporte nada a la realidad de cualquier contrato administrativo, y aun de cualquier relación contractual. Si el contratista ha gestionado bien ajustando sus costes ganará dinero y si no lo hace lo perderá. En cualquier contrato hay riesgo de ganar o perder dinero. Si lo que la ley quiere decir es que la Administración no puede cubrir las eventuales pérdidas del contratista, es correcto, pero no es una peculiaridad del contrato concesional que pueda definir qué es «riesgo operacional».

Esta conclusión no es baladí: la Junta Consultiva de Contratación Administrativa de la Generalitat de Catalunya analizó el concepto del riesgo operacional en relación con los contratos de concesión y otras categorías contractuales y a estos efectos dictó el informe 9/2016, de 1 de diciembre, en el que se concluía, entre otras cosas:

[...] no parece que pueda considerarse que se traslada el riesgo operacional solo con el traslado del riesgo de disponibilidad, es decir, determinando la retribución de la empresa contratista únicamente por el grado efectivo de disponibilidad de la obra o servicio objeto del contrato o por el cumplimiento de determinados estándares de calidad fijados previamente [...] Sin embargo, dado que el riesgo operacional se define como aquel que proviene de factores ajenos al control de las partes y de las incertidumbres del mercado, el riesgo de disponibilidad se podría entender que se encuentra incluido en el concepto de riesgo operacional la disponibilidad es debida a factores externos a la propia empresa contratista si fuera consecuencia del «riesgo tecnológico» [asumido]. 
Este informe se dictó el 1 de diciembre de 2016, en el período en el que la Directiva de Concesiones ya estaba fuera del periodo de transposición y analiza el concepto de riesgo operacional de la Directiva Comunitaria que es, como hemos señalado, literalmente el mismo que se ha recogido finalmente en la Ley de contratos española. Ciertamente, al dictarse este informe no se conocía lógicamente el art. 267 de la nueva Ley de contratos al que nos hemos referido anteriormente, de tal manera que debe entenderse que la interpretación que hizo la Junta Consultiva de Contratación Administrativa de la Generalitat de Catalunya no es una interpretación consistente con el actual texto de la ley. Ahora bien, esto no quiere decir que no pueda ser una interpretación plausible de la definición comunitaria por más que en nuestra opinión las consideraciones que se hacen en el informe no las podamos compartir.

\section{CONCESIÓN DE OBRAS, RIESGO OPERACIONAL Y DÉFICIT PÚBLICO: INTERRELACIÓN CON EL SISTEMA EUROPEO DE CUENTAS}

Los conceptos de riesgo de demanda y de suministro o disponibilidad se han tomado por la Directiva de Concesiones del Reglamento Comunitario por el que se regula el Sistema Europeo de Cuentas, Reglamento 549/2013 (SEC 2010) y del llamado «Manual del Sistema de Cuentas» que aprueba la autoridad estadística europea, Eurostat, en desarrollo del Reglamento SEC. Siendo esto así, es importante aclarar que el SEC y su Manual no tienen impacto alguno en las normas de contratación pública y por tanto tampoco en la definición de qué tipo de contrato puede tipificarse como de concesión de obra pública o no. El sistema normativo de contratación pública y el estadístico son dos sistemas de normas distintos con finalidades distintas y que no pueden utilizarse de manera "cruzada» para hacer interpretaciones del sistema ajeno?.

Es erróneo afirmar que la Directiva Comunitaria o la nueva LCSP requieren la traslación de riesgo operacional porque de esa manera se asegura la no consolidación presupuestaria de las concesiones. No es así, puede perfectamente ocurrir que un contrato traslade riesgo operacional a los efectos de contratación pública y, sin embargo, esa traslación de riesgo operacional no implique que a los efectos de contabilidad pública se produzca una desconsolidación presupuestaria. La razón es la expuesta, se trata de sistemas norma-

9 Sobre el particular puede verse mi artículo, J. Martínez Calvo (2005), "Crónica del caso Mintra. Hacia la construcción de un Derecho Administrativo Financiable», Revista de Administración Pública, 167, págs. 369-402. 
tivos distintos que tienen finalidades distintas y que, sobre todo, regulan de forma distinta qué riesgos y cómo deben trasladarse ${ }^{10}$.

La Administración contratante está obligada, como veremos más adelante, a preparar un estudio de viabilidad en el que se analice entre otras cosas qué efectos presupuestarios va a generar y qué impacto tendrá la concesión en el déficit, pero el impacto en el déficit de los contratos concesionales no es, desde un punto de vista legal, un requisito que condicione la naturaleza jurídica del contrato de concesión de obras ${ }^{11}$.

10 Por ejemplo, Eurostat, y en España la IGAE, han desarrollado conceptos para desconsolidar los contratos tales como la traslación de riesgo de cierre financiero, el pago teórico "cero» o la necesidad, en las obras de reparación, de generación de un activo nuevo superior al 50\% del existente que son completamente ajenos a lo regulado en la LCSP. De hecho, la LCSP habla de traslación de riesgo de «suministro» y el SEC de traslación de riesgo de «disponibilidad" como riesgo complementario o de demanda. Son sistemas conceptuales distintos que actúan en paralelo sobre las concesiones sin afectarse mutuamente. Los problemas que esta dualidad de sistemas genera los desarrollé ampliamente en el artículo citado en la nota anterior.

11 Discrepo de las conclusiones que alcanza A. Huergo Lora en su artículo, ya citado, «El riesgo operacional en la nueva Ley de Contratos del Sector Público», en la medida en la que considera (pág. 51) que un contrato concesional se desnaturaliza si no hay riesgo de demanda y que una concesión que se basa en pagos por disponibilidad «tiene de concesión poco más que el nombre al que saca partido a efectos financieros». En la práctica internacional de concesiones, los contratos licitados bajo un criterio de traslación de riesgo de demanda son minoritarios en relación con los que asignan un riesgo de disponibilidad. Si tenemos que cambiar el nombre de dichos contratos y en vez de concesiones hay que llamarlos «contresiones», hagámoslo, pero son desde luego estructuras obligacionales muy útiles para la dotación por parte del sector público de infraestructuras públicas y su uso es imprescindible. Por otro lado, la insistencia (no solo en este autor) en que hay cierto "truco» o «impostura» en estos contratos por sus efectos en la contabilidad nacional y el déficit, debe corregirse. Este no es un problema jurídico sino contable y la contabilidad es por definición una convención. Por ello no deben mezclarse los planos jurídico y contable como explico en mi artículo, ya citado, "Crónica del caso Mintra». Sobre las mejores prácticas internacionales en contratos concesionales puede verse (2017) «Benchmarking Public-Private Partnership», Word Bank, y (2016) «Allocating Risk in Public Private Partnerships», GHI-G20. Ambos disponibles en https://ppp.worldbank.org/public-private-partnership/library. Como se puede concluir de los amplísimos análisis de ambos estudios, en la práctica internacional de contratos concesionales, los sistemas de traslación de riesgo son también mayoritariamente por disponibilidad en América, África o Asia, lugares donde el SEC 2010 no es sospechoso de colaborar en truco contable alguno. 


\section{NOVEDADES EN EL RÉGIMEN JURÍDICO DE LA PREPARACIÓN, LICITACIÓN Y ADJUDICACIÓN DEL CONTRATO DE CONCESIÓN DE OBRAS}

Adicionalmente a las novedades que hemos expuesto sobre la naturaleza jurídica del contrato de concesión de obra pública, la nueva LCSP ha introducido novedades en su régimen jurídico que pueden dividirse en dos bloques: aquellas relativas a los actos preparatorios y de licitación del contrato (que analizaremos en el presente apartado) y, en segundo lugar, aquellas novedades relativas al régimen de obligaciones materiales entre las partes (que analizaremos en el apartado III).

\section{ESTUDIO DE VIABILIDAD DEL CONTRATO}

Como requisito previo a la licitación del contrato de concesión de obras, las sucesivas Leyes de Contratos han exigido, desde 2003, la redacción de un «Estudio de Viabilidad» que debe someterse a información pública. El contenido de dicho estudio (art. 128 de la Ley de 2007 y actual art. 247) se ha centrado en la definición de los elementos económicos, técnicos y ambientales que configuran el contrato de concesión y que deben permitir la valoración y juicio sobre la oportunidad y conveniencia de dicha concesión. La nueva ley amplía alguno de los contenidos que el estudio de viabilidad tiene que incluir y que hasta la fecha no se exigían. Los dos primeros son especialmente relevantes:

a) En primer lugar, requiere, de forma novedosa, la «justificación de las ventajas cuantitativas y cualitativas que aconsejan la utilización del contrato de concesión de obras frente a otros tipos contractuales, con indicación de los niveles de calidad que resulta necesario cumplir, la estructura administrativa necesaria para verificar la prestación, así como las variables en relación con el impacto de la concesión en la estabilidad presupuestaria».

La ley no pide aquí (como se hacía para el desaparecido contrato de colaboración público-privada) que se justifique que no se pueden utilizar otros contratos para alcanzar los fines de la Administración, pero sí se requiere que se analicen y señalen dichas ventajas frente a otros tipos contractuales. Es una forma de lo que las prácticas internacionales en contratos concesionales (Public Private Partnership) denominan "Value for Money» del contrato de concesión que debe aplaudirse.

En lo que se refiere al contenido de este estudio previo genera, sin embargo, grandes dudas la solicitud de que se analicen las variables en relación con el impacto de la concesión en la estabilidad presupuestaria. Debe tenerse en cuenta que, por definición, al someterse a información pública un estudio de viabilidad no se han redactado los pliegos y es imposible valorar sin dichos 
pliegos el impacto en la estabilidad presupuestaria. De hecho, el objetivo conceptual del estudio de viabilidad es la decisión sobre si se sigue adelante o no con el proyecto para la cual no tiene sentido redactar pliego alguno. Adicionalmente, como es conocido por cualquier operador jurídico que trabaje en el mundo concesional, el grupo de trabajo sobre estabilidad presupuestaria que, con miembros de IGAE, INE y Banco de España, hace la valoración de los impactos presupuestarios de las concesiones que se liciten no emiten opiniones hasta que, como es lógico, no se disponga de unos pliegos.

b) La segunda novedad de la ley consiste en requerir el cálculo de «el valor actual neto de todas las inversiones, costes e ingresos del concesionario, a efectos de la evaluación del riesgo operacional, así como los criterios que sean precisos para valorar la tasa de descuento». Como ya anunciábamos al referirnos a la definición del nuevo concepto de «riesgo operacional», esta idea se desgrana a lo largo de diversos artículos de la nueva ley. El primero de ellos es esta mención en el estudio de viabilidad.

La ley introduce aquí dos conceptos clave para entender el funcionamiento de un contrato concesional que hasta la fecha no aparecía en nuestra legislación: el «valor actual neto» y la «tasa de descuento». La principal consecuencia de la introducción de los nuevos conceptos es que en nuestra opinión lo razonable es entender que la tasa de descuento del proyecto que la Administración ha utilizado en su estudio de viabilidad debe ser sin duda un elemento a considerar para los reequilibrios futuros. Es verdad que la tasa de descuento de cualquier inversión mide básicamente dos factores diferentes: en primer lugar, el coste del dinero (precio de la financiación) y, en segundo lugar, el propio coste del capital, es decir, el beneficio esperado del inversor. En todo caso, al menos en lo que se refiere a la fijación de la parte que remunera el capital, esta tasa de descuento fijada por la Administración en su estudio de viabilidad debe ser sin duda una referencia de cara a cualquier reequilibrio ${ }^{12}$.

c) La tercera novedad se refiere a la necesidad de que se analice la existencia de una posible ayuda de Estado y la compatibilidad de la misma con el Tratado de la Unión Europea, en los casos en los que para la viabilidad de la concesión se contemplen ayudas a la construcción o explotación de la misma ${ }^{13}$.

12 No comparto la opinión de Lavilla Rubira (2018: 1422), cuando considera que la tasa de descuento deberá ser la referida en el art. 282, a) de la LCSP. Por definición, la tasa de descuento deberá estar referenciada al riesgo que tiene el proyecto (mayor a mayor riesgo y por tanto mayor remuneración del capital). Cada proyecto debe tener una diferente tasa interna de retorno atendiendo a sus características y la evolución de los mercados y no tiene sentido que haya una genérica igual para toda concesión.

13 Aun no siendo una novedad de la LCSP 2017, debe destacarse que la Disposición Final 9.12 de la Ley 40/2015 creó la Oficina Nacional de Evaluación, órgano todavía 


\section{VALOR ESTIMADO DEL CONTRATO}

Frente al modelo tradicional en el que el valor estimado en la concesión de obra pública se calculaba en relación con el valor de la inversión, la nueva ley, en línea con los requerimientos de la Directiva de Concesiones, señala en el art. 101, 1, b) que «en el caso de los contratos de concesión de obras [...] el órgano de contratación tomará el importe neto de la cifra de negocios, sin incluir el Impuesto sobre el Valor Ańadido, que, según sus estimaciones, generará la empresa concesionaria durante la ejecución del mismo como contraprestación por las obras y los servicios objeto del contrato, así como de los suministros relacionados con estas obras y servicios».

Es decir, no se trata ya de valorar la inversión sino la totalidad de ingresos, medidos como ingresos corrientes, que va a recibir la concesionaria a lo largo de la vida de la concesión. La cifra resultante va a ser, con mucho, muy superior a la cifra que regulaba la antigua ley.

En relación con esta novedad, la consecuencia fundamental es que este valor estimado va a ser en cualquier contrato concesional una cifra muy alta en relación con el valor de la inversión. Es, además, necesario que se incluya en el anuncio de licitación. Esto hará necesario que los órganos de contratación realicen una «didáctica» mayor sobre el significado de esta cifra, pues en caso contrario puede entenderse mal el coste real de una concesión.

\section{PLAZO DE PRESENTACIÓN DE OFERTAS}

La nueva LCSP de 2017, también en línea con lo previsto en la directiva de concesiones ${ }^{14}$, establece en el art. 156 los plazos mínimos de presentación de proposiciones y de publicación del anuncio de licitación.

Centrándonos en los contratos armonizados (como ya hemos dicho, es muy difícil que, en la práctica, con la nueva ley, existan casos de concesiones no armonizadas), la ley, de forma poco justificada, establece que para los con-

no constituido al escribirse estas páginas, que, entre otras cosas, debe, con carácter previo a la licitación de los contratos de concesión de obras y servicios, informar preceptivamente de las concesiones en las que se hagan aportaciones públicas o apoyos a la financiación o en los que la tarifa sea asumida parcial o totalmente por el poder adjudicador y el importe de las obras sea superior a un millón de euros (actual art. 333 LCSP). España es uno de los pocos países en los que hasta la fecha no existe un órgano especializado en el apoyo a la estructuración de contratos concesionales. La ONE, adecuadamente dotada, debería ser el órgano que superara esta carencia de nuestro sistema institucional.

14 Artículo 39,3 de la Directiva 2014/23/UE. 
tratos de concesión de obra, en los procedimientos abiertos el plazo mínimo de presentación de proposiciones lo reduce a 30 días frente a los 35 días del resto de contratos armonizados.

Es sorprendente que los plazos mínimos para presentar ofertas en los contratos de concesión en la nueva ley se hayan modificado en sentido contrario a la regulación del antiguo art. 164. En la antigua ley el plazo mínimo general era de 36 días para los contratos en general, excepto para los concesionales que era de 52 días.

Desde luego es una norma poco consistente con la regulación general de la ley, que ha reforzado todos los actos preparatorios de los contratos concesionales, es decir, «preparación reflexiva y pausada» de dichos contratos. No tiene ningún sentido que la Administración solicite las ofertas de un contrato a gestionar en 15 o 20 ańos en 30 días. Sin embargo, lo cierto es que la experiencia demuestra que la presión que tienen los responsables políticos para reducir plazos, por ejemplo, en fechas preelectorales, es muy alta y, será difícil que no se llegue en ocasiones a estos plazos con el consiguiente riesgo de ofertas con insuficiente estudio. Este artículo debería ser objeto de modificación.

\section{PROPUESTAS DE INICIATIVA PRIVADA}

En la Ley de contratos de 2007 ya se preveía la posibilidad de que los particulares propusieran a la Administración proyectos de concesiones. El art. 128 admitía la iniciativa privada en la presentación de estudios de viabilidad económico-financiera. La nueva regulación recogida en el art. 247 de la nueva ley introduce una novedad que podría llegar a ser relevante en nuestra práctica concesional y debe ser positivamente valorada. Señala la ley que el autor de la iniciativa privada "tendrá derecho en la correspondiente licitación a cinco puntos porcentuales adicionales a los obtenidos por aplicación de los criterios de adjudicación establecidos en el correspondiente pliego...».

Es decir, con este artículo se rompe el principio de concurrencia en igualdad de condiciones (hasta la fecha dogma de nuestro sistema de contratación pública) en aquellos casos en los que una iniciativa privada sea objeto de consideración. La novedad es positiva, pues el sector privado por definición tiene capacidad para proponer al sector público, en el ámbito de su actividad, soluciones innovadoras a problemas de carencia o gestión de infraestructuras públicas, pero sin un incentivo suficiente (el dudoso pago de una parte de los costes de preparación de oferta no lo es, desde luego) no habrá un sector privado interesado en aportar su conocimiento. La ley rompe en este punto un cierto tabú que es el de la prevención de las relaciones entre Administración y empresas a la hora de diseñar y licitar un contrato público. No es ilegal, sino 
que se incentiva en la ley, que el sector privado proponga contratos a la Administración con el objetivo lícito, e incentivado por la ley, de conseguir la firma del mismo y que por ello se sitúe en mejor posición de cara a la adjudicación del contrato. Esta es la novedad y debe ser aplaudida ${ }^{15}$.

\section{ACREDITACIÓN DE SOLVENCIA}

De acuerdo con el art. 86,3 de la nueva ley, el procedimiento de aportación de solvencia en los contratos concesionales puede cambiar de forma radical a la manera en que actualmente se solicita por las administraciones públicas:

En los contratos de concesión de obras y concesiones de servicios en los que puedan identificarse sucesivas fases en su ejecución que requieran medios y capacidades distintas, los pliegos podrán diferenciar requisitos de solvencia, distintos para las sucesivas fases del contrato, pudiendo los licitadores acreditar dicha solvencia con anterioridad al inicio de la ejecución de cada una de las fases.

En los contratos concesionales típicamente hay tres fases de ejecución del contrato perfectamente definidas: la fase de diseño o proyecto en la que el concesionario desarrolla el anteproyecto aprobado por la Administración; la fase de ejecución de las obras y, por fin, una vez terminadas estas, la fase de prestación del servicio. Son tres fases en las que las capacidades son claramente determinadas: la primera es típicamente la de ejecución de proyectos/ingeniería, la segunda de construcción y la tercera estará vinculada al tipo de servicios en los que consista la concesión.

Esto quiere decir que si la Administración utiliza esta nueva posibilidad, en los pliegos sería posible que el licitador no aportara directamente la solvencia necesaria para construir las obras o prestar los servicios objeto de la concesión con su oferta, sino que se limitará a comprometerse a hacerlo. En el extremo sería perfectamente viable que, por ejemplo, un licitador aportara con su oferta las credenciales requeridas relativas a su capacidad para desarrollar el proyecto de ingeniería, pero, sin embargo, respecto de la capacidad de

15 Mantiene la opinión contraria Lavilla Rubira (2018: 1423), por las dudas que los principios de igualdad de trato y no discriminación le generan en relación con ese incentivo. Creo que la experiencia demuestra que la institución de la iniciativa privada sin incentivo vinculado a la adjudicación es estéril. En otras jurisdicciones, sobre todo Perú, Colombia o Chile, sin embargo, es una institución útil precisamente porque sí existen esos incentivos. En cuanto a la ruptura del principio de igualdad de trato, mi opinión es que el esfuerzo en ofrecer una solución novedosa y analizada en detalle a la Administración pública justifica el test de razonabilidad del trato diferenciado. 
construcción de las obras o de prestación del servicio objeto de la concesión únicamente aportará el compromiso de integrar con medios externos (en el momento de comienzo de dicha prestación) dicha solvencia.

Pues bien, con la nueva regulación puede ser perfectamente plausible que un fondo de inversión (sin capacidad alguna para construir la obra pública) lidere la presentación de una oferta a una gran concesión, incorporando solo progresivamente a las distintas empresas que realizarían la construcción o la prestación de los servicios. De esta manera el fondo de inversión sería el responsable de contratar —entre las empresas que tengan solvencia suficiente- los constructores y los prestadores de servicios en las sucesivas fases de ejecución de los contratos. Es importante este artículo, pues en el mismo se rompe una tradición en nuestro modelo de contratación administrativa según el cual la concesión de obras se contrata necesariamente con empresas constructoras. Como cierre, y con todo el sentido, la ley regula de forma contundente el incumplimiento de este requerimiento de aportar la solvencia por el contratista: «En el caso de aquellos empresarios que acogiéndose a la posibilidad prevista en el párrafo anterior, no acreditaran su solvencia antes del inicio de la ejecución de la correspondiente fase, se resolverá el contrato por causas imputables al empresario».

\section{LOTES}

Uno de los objetivos de política legislativa de la exposición de motivos de la ley (y también de la nueva directiva "clásica») ha sido el del favorecimiento de las pymes en la contratación pública. Para ello se ha redactado, sobre todo, el nuevo art. 99 de la LCSP de 2017, que exige con carácter general, siempre que la naturaleza del contrato lo permita, que cada una de sus partes se ejecuten de forma independiente. Para ello se propone la aplicación, siempre que sea posible, de lotes. Es decir, la regla general es la de la licitación de los contratos por lotes si es posible.

Frente a esta regla general se prevén una serie de excepciones que deben motivarse según los preceptos de la ley. Por excepción, en el caso de los contratos de concesión de obras no es necesario justificar ninguna razón para la no división en lotes ${ }^{16}$ : «No obstante lo anterior, el órgano de contratación podrá no dividir en lotes el objeto del contrato cuando existan motivos válidos, que

16 No ocurre lo mismo para los contratos de concesión de servicios, donde sí sería necesario realizar la correspondiente motivación en el expediente. No parece que tenga mucho sentido que esta exclusión sea distinta en los de concesión de obras y de servicios. 
deberán justificarse debidamente en el expediente, salvo en los casos de contratos de concesión de obras».

\section{GARANTÍAS}

En la nueva LCSP, art. 107,4, se flexibiliza la regulación del régimen de las garantías definitivas en los contratos concesionales, en concreto: «En la concesión de obras y en la concesión de servicios el importe de la garantía definitiva se fijará en cada caso por el órgano de contratación en el pliego de cláusulas administrativas particulares, en función de la naturaleza, Es decir, la nueva ley flexibiliza, remitiendo al pliego, los requerimientos en relación con la garantía definitiva en los contratos concesionales. Esto tiene todo el sentido, pues el modo tradicional de fijar una garantía como un $5 \%$ del valor de la inversión no tiene sentido alguno en un contrato concesional, pues en los contratos de concesión de obras en los que por definición hay varias fases prestacionales en el contrato lo lógico es que la garantía que la Administración debe requerir, para la protección del interés general, varíe. ¿Tiene sentido requerir, como es hasta la fecha ordinario, un 5\% del valor de la inversión una vez que la obra está construida a plena satisfacción de la Administración y ya en funcionamiento? No lo tiene en una obra que es de dominio público por definición y respecto de la que la Administración tiene las mayores potestades patrimoniales de protección y recuperación. Por tanto, sería conveniente definir como buena práctica la reducción de dicha cuantía, cosa que de acuerdo con el art. 107,4 de la nueva ley es perfectamente factible. Además de ajustado a las mejores prácticas internacionales en materia concesional.

\section{CRITERIOS DE ADJUDICACIÓN: EL CICLO DE VIDA DEL PRODUCTO}

Una de las grandes transformaciones conceptuales que ha incluido la nueva ley de contratos es la que se refiere a los criterios de adjudicación del contrato que se regulan en los arts. 145 y siguientes de la nueva ley. La regla de la adjudicación de los contratos a la "oferta económicamente más ventajosa» se ha sustituido por la «mejor relación calidad-precio». En este sentido, frente a lo que ha sido habitual en nuestra práctica de contratación pública de los últimos ańos, difícilmente encaja en la nueva ley la utilización de «subastas encubiertas», práctica según la cual se incentiva de forma desproporcionada el precio entre los criterios de adjudicación, valorando en muy menor medida la calidad técnica de lo ofertado. Tal y como señala el inciso final del art. 145,2: «[...] los criterios cualitativos deberán ir acompañados de un criterio relacionado con los costes, el cual, a elección del órgano de contratación, podrá ser el precio o un planteamiento basado en la 
rentabilidad, como el coste del ciclo de vida calculado de conformidad con lo dispuesto en el art. 148».

Pues bien, aunque este nuevo criterio no es solo aplicable a los contratos concesionales, sí puede decirse que son los contratos para los que es aplicable de manera más natural. Esto es así porque precisamente el mayor valor por dinero es el criterio clave para tomar la decisión de licitar una concesión. Dicho mayor valor por dinero de la concesión (que es el criterio que exige el art. 247 de la ley que se pruebe en el estudio de viabilidad para licitar una concesión) se prueba básicamente en que el gestor pueda optimizar el coste de la obra a largo plazo, de tal manera que las decisiones estratégicas del concesionario permitan compensar los siempre mayores costes de financiación que tiene el sector privado.

Todo ello es lo que se puede medir adecuadamente con el criterio del coste del ciclo de vida que regula el art. 148 de la ley. Aunque el literal de la ley establece que dicho coste del ciclo de vida es solo una opción como criterio de adjudicación, en nuestra opinión más bien debería considerarse como el único criterio razonable para adjudicar una concesión. Ciertamente su correcta definición entrańa dificultades conceptuales porque hay que entender en profundidad el sentido y funcionalidad de la obra para diseñarla correctamente, dicho lo cual la complejidad y la necesaria reflexión previa profunda es una característica propia de todo contrato concesional, de tal manera que esta exigencia es natural al propio contrato.

El art. 148 define el ciclo de vida de un producto (entiéndase para las concesiones de obra):

Todas las fases consecutivas o interrelacionadas que se sucedan durante su existencia y, en todo caso, la investigación y desarrollo que deba llevarse a cabo, la fabricación o producción, la comercialización y las condiciones en que ésta tenga lugar, el transporte, la utilización y el mantenimiento, la adquisición de las materias primas necesarias y la generación de recursos, todo ello hasta que se produzca la eliminación, el desmantelamiento o el final de la utilización.

Los costes que prevé el 148,2 son los siguientes: los de adquisición, de utilización, de mantenimiento y los de final de vida. En realidad, cualquier coste directo parece claramente amparado por la norma. Junto con los costes directos aparece también regulada la posibilidad de que se valoren, esto es lo más novedoso, costes imputados a externalidades del producto, servicio u obra siempre que el valor monetario pueda determinarse.

En resumen, el valor del coste objetivo de la concesión de obra, evaluable mediante fórmulas, puede incluir elementos como el coste de las reparaciones, el valor de desmantelamiento al final del contrato o externalidades ambienta- 
les (pensemos por ejemplo en una carretera cuyo firme permite el ahorro de combustible ${ }^{17}$ ).

Estructurar este sistema de valoración que la ley establece como preferente plantea retos intelectuales (jurídicos y financieros) relevantes. Téngase en cuenta que el precio que se licita en una concesión suele ser el valor de la tarifa a pagar por el uso de la obra (pague usuario o Administración). Dado que lo que remunera esa tarifa es un valor corriente de pagos de un modelo financiero complejo a veinte o treinta años, identificar el impacto en la tarifa de una externalidad ambiental no es fácil. En este punto debe destacarse la importancia de la rápida puesta en marcha de la Oficina Nacional de Evaluación para que emita pronto criterios y orientaciones sobre cómo es posible diseñar estas fórmulas de valoración. En todo caso debe tenerse en cuenta que al criterio tradicional de qué tarifa se ofrece en la oferta se ańadirán otros, que también puntuarán modulando (con las correspondientes fórmulas de descuento para obtener el valor monetario en valor actual neto) la puntuación de dicha tarifa de entrada.

\section{NOVEDADES EN EL RÉGIMEN JURÍDICO-MATERIAL DEL CONTRATO}

\section{PLAZO DEL CONTRATO}

Según el nuevo art. 29,6:

[...] los contratos de concesión de obras y de concesión de servicios tendrán un plazo de duración limitado, el cual se calculará en función de las obras y de los servicios que constituyan su objeto y se hará constar en el pliego de cláusulas administrativas particulares. Si la concesión de obras o servicios sobrepasara el plazo de cinco años, la duración máxima de la misma no podrá exceder del tiempo que se calcule razonable para que el concesionario recupere las inversiones realizadas para la explotación de las obras o servicios, junto con un rendimiento sobre el capital invertido, teniendo en cuenta las inversiones necesarias para alcanzar los objetivos contractuales específicos.

17 Un ejemplo de este tipo de criterio de adjudicación sería aquel según el cual en los criterios cuantitativos (no en la oferta técnica, por tanto) una oferta más cara pueda tener más puntos que una más barata porque demuestre que a lo largo de la vida de la concesión el ahorro en combustible por los usuarios a la vista del tipo de firme que se instale sea mayor que la diferencia de precio ofertada. 
A continuación se recogen en la ley determinados plazos máximos que coinciden con los existentes hasta la fecha: cuarenta años para concesión de obras que comprendan la construcción de obras es la regla general.

Frente al modelo previo de la Ley de contratos de 2003 y 2007 en el cual la duración de la concesión tiene un plazo máximo general de cuarenta años y, respetándolo, la Administración podía decidir qué plazo concreto de duración del contrato desea licitar, en el actual modelo este plazo no es libre para la Administración, sino que se limita por el tiempo necesario para recuperar las inversiones. Este límite solo actúa en aquellas concesiones que tengan una duración prevista de más de cinco ańos, no en las de menos (lo que en la práctica incluye a todas porque es muy inusual que se liciten concesiones con una duración menor de cinco años).

La norma, novedad conceptual relevante de la ley y directamente derivada de la directiva comunitaria, pretende promover la libre competencia y limitar las concesiones de plazo demasiado largo por sus efectos de «bloqueo del mercado" y de restricción de la competencia.

Estando claro el objetivo, sin embargo, la aplicación práctica de esta regla está llena de dificultades. ¿Cuál es el tiempo razonable para la recuperación de las inversiones? Pues depende del esfuerzo de pago que la Administración considere oportuno fijar. Veamos el problema desde la perspectiva de una concesión en la que el pago se realice por los usuarios (típicamente una autopista de peaje); si la Administración fija una tarifa máxima $X$, los años necesarios para recuperar la inversión (a la vista de los estudios de demanda disponibles) serán $Y$, pero si la Administración fija una tarifa el $20 \%$ superior a $X$ es muy probable que el plazo sea menor. Es decir, la Administración en este supuesto sigue teniendo una enorme libertad para definir cuál es el plazo razonable de recuperación de la inversión y, de hecho, lo definirá al fijar (y esta es una decisión administrativa discrecional) cuál es la tarifa máxima que los ciudadanos deben pagar por el uso de la autopista.

Más claro se plantea el problema en el caso de una concesión en la que la Administración plantee un pago por disponibilidad de la obra (típicamente puede ser una concesión para construir y mantener un hospital sin incluir servicios sanitarios); la Administración debe fijar en el estudio de viabilidad y pliegos la tarifa base de licitación, es decir, el precio que la Administración está dispuesta a pagar en un determinado plazo, y la cuantía de la misma será la que fijará el plazo máximo de recuperación de la inversión.

En todas las concesiones nos encontramos con un proceso de estructuración financiera de la concesión en el que es claro que la definición del esfuerzo presupuestario de referencia, en forma de precio, que la Administración o los usuarios van a pagar va primero, y el plazo va después. Y no tiene sentido hacerlo de otra manera. 
Esto nos lleva a la conclusión de que esta modificación de la ley en realidad no cambia en lo esencial la regulación previa de 2003/2007 ${ }^{18}$.

\section{CESIÓN DEL CONTRATO Y VENTA DE PARTICIPACIONES}

Adicionalmente al régimen de cesión de los contratos, donde no hay cambios relevantes, la nueva ley regula, lo que no hacía la Ley de 2007, la venta de participaciones de sociedades concesionarias en el nuevo art. 214,3. Como la antigua ley no hacía regulación explícita alguna de los requerimientos jurídicos para la venta de participaciones de sociedades concesionarias, era habitual que los pliegos establecieran normas para ello que, en la mayoría de los casos, eran confusas porque condicionaban la venta al cumplimiento de los requerimientos de la cesión del contrato «en lo que resulte aplicable». Esta remisión genérica e indefinida en la práctica significaba que la Administración, aun sin mucho convencimiento en la práctica, se veía obligada a hacer cierto control sobre la solvencia del cesionario en los casos de solicitud de venta de participaciones de sociedades concesionarias, a la vez que se solía requerir la aplicación del requisito de transcurso del $20 \%$ de la duración del contrato.

Esto último, aunque era comprensible por las dudas que generaba la posibilidad de que se entendiera que una no exigencia de dichos requisitos implicara algún tipo de incumplimiento de la ley (por más que, repetimos, la ley no regulaba en absoluto la venta de participaciones de las concesionarias), ha generado problemas en el mercado secundario de concesiones y en realidad producía importantes disfunciones a la hora de planificar las transacciones sobre paquetes accionariales en concesiones. El problema es de primer orden, pues el negocio concesional, como reconoce de forma explícita la ley ya en va-

18 Un caso especial es el que se originaría en un supuesto en el que la Administración licitara una concesión sobre una obra ya construida (pensemos en una autopista ya existente titularidad del Estado) en la que se solicita, como criterio de adjudicación, que el licitador pague un canon a la Administración. En este caso lo que ocurre es que por definición no hay plazo de recuperación de la inversión pues ésta ya está ejecutada. Sobre este tipo de concesión de obra pública surge una razonable duda de legalidad. Es cierto que el art. 289,3 de la nueva LCSP permite que «el concesionario abonará a la Administración concedente un canon o participación, que se determinará y abonará en la forma y condiciones previstas en el citado pliego y en la restante documentación contractual»; ahora bien, este artículo está recogido en el capítulo relativo a la concesión de servicios y no en el de la concesión de obras. ¿Puede licitarse una concesión de obras exigiendo dicho tipo de canon? En nuestra opinión no, ya que la supletoriedad de la regulación del contrato de concesión de obras respecto del de servicios está recogida en la ley, pero no viceversa. 
rios artículos, es un negocio con fases sucesivas distintas y una buena gestión de las mismas implica sin duda la necesidad de regular la eventualidad de que el especialista en construcción quizás ya no tenga sentido que esté en la fase de gestión del servicio, etc. Y, sobre todo, no recogía la suficiente flexibilidad para que los principales protagonistas de los proyectos de concesiones de infraestructuras a nivel mundial, los fondos de inversión, adquirieran de forma sencilla concesiones en España, lo que en un proceso de consolidación fiscal y desapalancamiento de la economía española como el vivido desde 2009 hasta fechas recientes no tenía sentido alguno que generara dudas legales.

La nueva Ley, como decimos, ha simplificado el régimen de venta de las concesionarias en los nuevos arts. 214,1, p3 y 250,1, c):

a) La regla general, que deberá estar explicitada en el pliego, es que en el supuesto de que los adjudicatarios hayan constituido una sociedad para la ejecución del contrato (supuesto ordinario en los contratos concesionales) es posible la venta de las participaciones en la sociedad.

b) Los pliegos deben regular el supuesto de que, por implicar un cambio de control sobre la concesionaria, esa cesión de participaciones deberá ser equiparada a una cesión contractual. Este supuesto se produce en todo caso cuando se venda el $51 \%$ de las participaciones. Dos puntualizaciones al respecto: (i) la equiparación a la cesión es solo a los efectos autorizatorios, no en relación al resto de requisitos, (ii) la venta de más de un 50\%, pero menos de un $51 \%$ de las participaciones, sin que se entienda muy bien, no necesariamente implica un cambio de control (art. 250,1, c).

c) Los pliegos podrán prever mecanismos de control de la cesión de participaciones que no impliquen un cambio de control en supuestos que estén suficientemente justificados. Es decir, si no hay cambio de control la regla general es la libertad de venta de las participaciones salvo que el pliego justifique la necesidad de control ${ }^{19}$.

En conclusión, la nueva ley incentiva explícitamente la posibilidad de venta de participaciones de concesionarias que, si no implican cambio de control, solo extraordinariamente pueden ser objeto de autorización por la Administración. Todo ello incentivará sin duda el mercado secundario de transacciones sobre concesiones y dará entrada a los fondos de inversión, y en general

19 Como señala Lavilla Rubira (2018), en el caso de venta de participaciones de las sociedades matrices de la concesionaria, la LCSP no establece límite alguno y por tanto no es posible establecer límites a su transmisibilidad al amparo del art. 38 de la CE. 
de inversores en infraestructuras que no sean promotores, en nuestro mercado de forma más clara, lo que es sin duda una buena noticia.

\section{MATRIZ DE RIESGOS}

El art. 250,1, m) introduce otra novedad importante en nuestro régimen concesional al señalar que los pliegos de condiciones administrativas particulares deberán incluir necesariamente: «[la] Distribución entre la Administración y el concesionario de los riesgos relevantes en función de las características del contrato, si bien en todo caso el riesgo operacional le corresponderá al contratista».

Esta previsión exige que la Administración, en los pliegos, abandone la cómoda postura de atribuir los riesgos en genérico a la concesionaria y explicite qué tipo de responsabilidad debe asumir cada una de las partes. Los contratos concesionales son por definición complejos, se ejecutan un plazo de tiempo largo e implican la gestión de múltiples riesgos. Tanto la Administración como el contratista privado optimizan su rol en el contrato si cada uno gestiona el riesgo sobre el que tiene mayor capacidad. En caso contrario, cualquier operador (público o privado) racional subiría el precio del contrato ${ }^{20}$.

Pese a lo obvio de esta reflexión, lo cierto es que en España esto no ha sido tan claramente asumido en los pliegos concesionales y la regla tradicional de que los contratos se deban gestionar «riesgo y ventura del concesionario» se ha interpretado, erróneamente, como que la Administración no debe gestionar o asumir ningún riesgo. Esto es contrario a cualquier buena práctica en la materia de gestión de contratos concesionales. Adicionalmente, no se trata solo de que cada parte asuma los riesgos que puede gestionar mejor, sino, sobre todo, que esté claro qué riesgo asume cada parte.

20 Por ejemplo: una discusión abierta en nuestro sistema concesional es la de si el riesgo del pago de las expropiaciones es un riesgo que debe asumir el concesionario o la Administración. Los enormes sobrecostes que generaron las expropiaciones en las autopistas de peaje concesionadas denominadas «Radiales de Madrid», causa relevante de que todas terminaran concursadas y resueltos los contratos, es el origen del debate. En mi opinión no parece que una modificación, como sucedió, de los criterios jurisprudenciales para el cálculo de los justiprecios basados en las expectativas de revalorización urbanística deba ser un riesgo que deba asumir un concesionario, dado que no puede hacer nada para reducirlo. Otra cosa, por ejemplo, sería que un retraso en la toma de posesión de las fincas expropiadas deba ser un riesgo que deba asumir un concesionario dado que en nuestro sistema de expropiación forzosa este plazo sí puede ser razonablemente gestionado por el beneficiario. 
Desde un punto de vista conceptual, por tanto, este artículo es relevante y viene en parte a superar la tradicional explicación acerca de que el origen del derecho al reequilibrio se estructura en dos conceptos básicos: «factum principis» y «riesgo imprevisible». Más allá del carácter didáctico de los conceptos, lo cierto es que en un contrato concesional bien estructurado al amparo de la nueva ley, y con un correcto desarrollo de este artículo 250,1, m), el derecho al reequilibrio o la ruptura del equilibrio, si así se prefiere, se producirá en aquellos casos en los que cualquiera de los riesgos que debe soportar cada parte genere un sobrecoste o beneficio por ruptura de la previsión del mismo. Es decir, cuando el art. 270 de la ley, en un artículo que no ha cambiado su tenor literal, señala que «el contrato de concesión de obras deberá mantener su equilibrio económico en los términos que fueron considerados para su adjudicación", esos "términos que fueron considerados» no pueden ser otros, en la base, que la asignación explícita de riesgos (matriz de riesgos) que pide la nueva ley que haga el pliego.

\section{MODIFICACIÓN DEL CONTRATO}

El régimen de modificación de los contratos administrativos ha sido uno de los temas más discutidos en nuestra contratación administrativa reciente. Justo dentro de este marco, la nueva ley modifica de forma pendular la regulación de los modificados y ha introducido un régimen mucho más flexible para los mismos. En efecto, frente a la regulación tradicional que se incluía para la modificación de los contratos en la Ley de 2007 (y que venía de los anteriores textos en vigor sin cambios), la Ley de economía sostenible de 2011 introdujo una restricción muy relevante en el régimen jurídico de los modificados en respuesta al inicio por parte de la Comisión Europea de ciertos expedientes de imposición de sanciones a España por incumplimiento de las directivas de contratación, al constatarse por parte de la Comisión la existencia de un gran número de modificados en los contratos públicos que, según los mismos, generaban una grave afección a la libre concurrencia, pues, entendía la Comisión, que en un número muy alto de contratos el objeto licitado y lo que se ejecutaba no tenía muchas veces nada que ver ${ }^{21}$.

21 Al respecto se puede ver J. M. Gimeno Feliú (2013), «La modificación de los contratos: Límites y derecho aplicable», en La contratación pública: problemas actuales, Consejo Consultivo de Madrid, págs. 83-140. También A. Cea Ayala (2012), «La nueva regulación de la modificación de los contratos", Contratación Administrativa Práctica, 118, págs. 46 y ss; J. Colas Tenas (2012), "La reforma de la legislación de contratos del sector público en la Ley de Economía Sostenible», Revista Española de Derecho Administrativo, 3, págs. 79-113; M. Garcés Sanagustín (2012), «El nuevo régimen jurídico de la modificación de los contratos públicos», en L. Parejo Alfonso y A. 
Sin embargo, la nueva regulación legal, y específicamente el art. 205, donde se regula el régimen de los modificados no previstos en el contrato, ha flexibilizado de manera muy relevante dicho régimen. En concreto el punto clave es el número 2 , a) $2^{\circ}$ de dicho artículo, que prevé, si se dan el resto de requisitos - ampliamente discrecionales - que el límite objetivo en relación con la cuantía del contrato será del $50 \%$ de su precio inicial, es decir muy elevado. De nuevo aquí, la aplicación "seguidista» de la Directiva parece que ha sido el criterio que se ha impuesto.

Dicho lo anterior, que la ley admita un mayor margen para la modificación de los contratos debe ser recibido de forma positiva en lo que se refiere a los contratos concesionales. Las novedades en esta materia tienen un especial efecto en relación con estos contratos, pues la duración de los mismos hace que las modificaciones sean en muchas ocasiones algo inevitable. Creo que este tipo de posturas maximalistas sobre lo inconveniente de las modificaciones contractuales deben ser ponderadas. No es posible diseñar contratos que vayan a ser ejecutados durante cuarenta años sin que modifiquen. Pensar lo contrario va contra el más sencillo sentido común. En quince, veinte o cuarenta años el Estado se transforma, también la sociedad, y es difícil que no lo hagan las obras públicas. El problema por tanto no está en la modificación sino en el correcto análisis del origen del problema y su imprevisibilidad y en que la solución tenga sentido y valore claramente su coste. Por todo ello se destaca de nuevo la importancia clave que en los contratos concesionales tiene una correcta y clara asignación de riesgos. Y ello, de nuevo, nos remite a que los pliegos en estos contratos deben estar redactados con atención y haciendo un análisis detallado del contexto del contrato ${ }^{22}$. Los contratos de concesiones

Palomar Olmeda (dirs.), El nuevo marco de la contratación pública, Barcelona: Bosch; J. A. Razquín Lizárraga (2011), «El nuevo régimen de modificación de los contratos del sector público tras la ley de economía sostenible», Revista Aranzadi Doctrinal, 8.

22 Una anécdota de la que el autor de este texto fue testigo explica bien el problema. Una de las concesiones cuyas dificultades de gestión son bien conocidas es la del «Tranvía de Parla», cuyos pliegos preparó en su momento el Consorcio de Transportes de la Comunidad de Madrid. El lector curioso puede comprobar que el pliego de tal concesión es literalmente igual que el licitado un año antes para la Línea 1 del Metro de Sevilla. La literalidad llega a tal punto que de hecho el contrato se denomina «Línea 1 del Tranvía del Parla» pese a que no se preveía la existencia de línea 2 alguna en Parla, sencillamente porque respecto del pliego del Metro de Sevilla no se hizo siquiera el esfuerzo de cambiar el título. En el momento de licitarse el contrato los responsables de estructurar la concesión decidieron que no era necesario redactar un pliego específico para Parla, el de Sevilla era suficiente. Esta manera de pensar, en la que se desprecia la importancia de la estructuración jurídica y financiera precisa de los contratos conce- 
deben ser en todo caso obras artesanas y no, como desgraciadamente es habitual, trabajos de confección industrial.

\section{LA RETRIBUCIÓN COMO PRESTACIÓN PATRIMONIAL DE CARÁCTER PÚBLICO}

Una de las más relevantes novedades de la ley es la caracterización jurídica que se hace de los ingresos del concesionario. Según el nuevo art. 267:

El concesionario tendrá derecho a percibir de los usuarios o de la Administración una retribución por la utilización de las obras en la forma prevista en el pliego de cláusulas administrativas particulares y de conformidad con lo establecido en este artículo, que se denominará tarifa y tendrá la naturaleza de prestación patrimonial de carácter público no tributario.

La Ley de 2007, en el art. 255 (y las anteriores en la misma línea), se limitaba a señalar que el concesionario tiene derecho a recibir de los usuarios o de la Administración una retribución en la forma prevista en el pliego. Utilizaba también el término tarifa, pero en el contexto de aquellos ingresos que se abonaban por los usuarios.

La novedad (más allá de generalizar la denominación de tarifa a cualquier ingreso del concesionario) ha sido la de que se les otorga por la ley la naturaleza de "prestación patrimonial de carácter público no tributario".

En paralelo a este artículo, la disposición final undécima modifica la disposición adicional primera de la Ley General Tributaria y la disposición final duodécima de la Ley de Haciendas Locales introduciendo un nuevo apdo. 6 en su art. 20. En ambas normas se desarrolla un marco general regulador de este tipo de prestación que, sin embargo, no tiene carácter tributario.

Para entender el sentido de la introducción y uso de este concepto en el campo de la contratación pública, es necesario retrotraerse a los efectos de la relevante y problemática STC 185/95. Esta sentencia, muy resumidamente, interpretó el art. 31.3 de la Constitución contrastando la constitucionalidad del contenido de la Ley de tasas y precios públicos de 1989 y concluyó que la reserva de ley era un requisito constitucional para la imposición de obligaciones coactivas de pago por parte de la Administración siempre que dichas obligaciones coactivas tuvieran unas características de necesidad básica o reca-

sionales ha sido relativamente común entre nosotros. Seguramente el distinto esfuerzo que los responsables públicos respectivos pusieron en estos dos casos a la preparación de un contrato ha influido relevantemente en que la concesión del Metro de Sevilla haya sido muy exitosa y la de Parla muy problemática. 
yeran sobre el uso de bienes de dominio público. La adaptación de la doctrina constitucional que hizo el legislador, en la práctica, hizo que se calificaran la casi totalidad de prestaciones coactivas existentes en dicho momento como tasas (prestaciones de carácter público tributarias), dejando como categoría muy residual los precios públicos que recaían sobre bienes del mercado.

Esta doctrina, con el paso del tiempo, ha generado una larga serie de problemáticas resoluciones judiciales, modificaciones normativas e interpretaciones de la Administración Tributaria en torno a la naturaleza jurídica de las cantidades que los ciudadanos pagan por el abastecimiento de agua potable ${ }^{23}$. Sin que sea el momento en extenderse sobre esta cuestión, lo cierto es que la caracterización de todos los ingresos de los concesionarios como prestaciones patrimoniales de carácter público no tributarias ha resuelto en buena medida el problema planteado en este tipo de contratos de abastecimiento de agua potable. Y esto porque al no tener ya carácter tributario los problemas de gestión y cobro, y en parte también la actualización, se simplifican enormemente para los gestores de este tipo de contratos. Otra cosa es la complejidad o dudas que, sin embargo, genera esta decisión en otros contratos concesionales respecto de los cuales la naturaleza jurídica de la retribución no ha planteado ningún problema hasta la fecha.

Fruto del espacio conceptual que la STC 185/95 dejaba para la existencia de prestaciones de carácter público no tributarias, el ordenamiento jurídico ya había utilizado, sin mucha precisión técnica, el concepto de prestación patrimonial de carácter público sectorialmente, destacadamente para regular determinados ingresos del sistema eléctrico ${ }^{24}$. La nueva Ley de contratos (modificando la LGT y la LHL) incorpora y regula con mayor precisión este concepto y, por ello, en realidad da una nueva dimensión a la figura haciéndola operativa en el marco del ordenamiento jurídico.

La definición del nuevo concepto se hace en la DA 1 de la LGT que senala que las prestaciones patrimoniales de carácter público son aquellas que se exigen con carácter coactivo, lógicamente por el sector público. Hasta ahora el legislador había entendido que todas ellas son las tributarias (tasas, contribu-

23 Sobre esta problemática, J. Tornos Mas (2011), «La tarifa como forma de retribución de los concesionarios», El Cronista del Estado social y democrático de derecho, 24, págs. 22-29, e «Informe sobre la contraprestación del servicio de abastecimiento domiciliario de agua: la sentencia del Tribunal Supremo de 23 de noviembre de 2015», La Administración al día, INAP, 17 de marzo de 2016.

24 Un completo análisis de la cuestión antes de la modificación de la LCSP en R. Gómez-Ferrer Rincón (2010), «Las prestaciones patrimoniales públicas de naturaleza no tributaria», en X Congreso de la Asociación Española de Profesores de Derecho Administrativo. 
ciones especiales e impuestos). Con el nuevo régimen legal, el legislador introduce formalmente también las no tributarias que son «las demás prestaciones que exigidas coactivamente respondan a fines de interés general».

Al margen de la peculiaridad del funcionamiento de la nueva categoría en el ámbito de la LHL, donde se sigue haciendo referencia a los servicios públicos, cuestión que excede a este trabajo, esta calificación del precio en los contratos concesionales como "prestación patrimonial de carácter público" debe ser valorada críticamente:

a) Porque calificar en la LCSP de manera general como de ingresos patrimoniales de carácter público todos los precios (tarifas) en los contratos concesionales no se justifica por la resolución de un problema puntual de un tipo de contratos (las concesiones de abastecimiento de agua potable) y no parece que haya un motivo que los justifique de manera general.

b) Desde un punto de vista de la financiabilidad de las concesiones de obra, la nueva categoría genera dudas a la hora de establecer las garantías habituales que los bancos establecen en los contratos de "Project Finance». Como es sabido, en una financiación de proyecto ordinaria — estructura jurídica habitual a través de la que se recaban los fondos para los contratos concesionales - todos los ingresos de la concesionaria se pignoran en favor del financiador. No hay dudas sobre que un precio privado o tarifa se puede pignorar en garantía de una deuda y así se ha hecho habitualmente. Más dudas genera la cuestión de si una prestación patrimonial de carácter público puede pignorarse. No puede pignorarse sin duda una de carácter tributario, pero si ésta fuera de carácter no tributario - las tarifas de un contrato concesional-, la respuesta es más dudosa. El problema se genera en el hecho de que se trata de «prestaciones que exigidas coactivamente respondan a fines de interés general». Veamos la diferencia: si se trata de un precio, lo pague un usuario del servicio o la Administración, no parece que haya dudas acerca de esta pignorabilidad, ahora bien, si la prestación es exigida coactivamente para fines de interés general, ¿puede un acreedor hacer suya esta cantidad por impago de una deuda? Podría argumentarse que el carácter finalístico y coactivo no permitiría que la obligación de pago se mantuviera frente al banco que no es el concesionario. Es un tema vidrioso, pero, aun aceptando que este argumento tiene cierto peso, en nuestra opinión, no existiendo una prohibición expresa, como sí la hay para la pignoración de tributos, la prenda sobre prestaciones patrimoniales de carácter público es posible legalmente pese a las dudas expuestas. 


\section{REVISIÓN DE PRECIOS}

El régimen de revisión de precios en los contratos concesionales se desarrolla en el art. 289 de la nueva LCSP, que, a su vez, hace una remisión en bloque a las previsiones generales sobre revisión de precios en los contratos, arts. 103 a 105.

Paradójicamente es a los contratos concesionales a los que afecta de manera principal el régimen de revisión general de los precios de los contratos. La razón es que la nueva ley limita la revisión de precios a los contratos de obras (donde, sin embargo, no hay novedades, pues se siguen aplicando las tradicionales fórmulas polinómicas), a algunos tipos muy específicos de contratos de suministros y, en tercer lugar, a los contratos en los que el periodo de recuperación de la inversión sea igual o superior a cinco años, es decir, básicamente a los concesionales.

La regulación de la revisión de precios en los contratos concesionales se completa, por remisión de la Ley de contratos, en la Ley 2/2015, de 30 de marzo, de desindexación de la economía española y a su reglamento de desarrollo, aprobado por Real Decreto 5/2017, de 3 de febrero, que desarrolla la Ley de Desindexación (en adelante, el Reglamento de Desindexación).

Es más, la propia LCSP hace una referencia cruzada al Reglamento de Desindexación cuando en el art. 29.9 regula la duración de los contratos de concesión de obra y de servicios de más de cinco años y establece que el periodo de recuperación de las inversiones a efectos de determinar el plazo máximo de duración de estos contratos de concesión será el que resulte de aplicar la fórmula fijada en el art. 10 del Reglamento de Desindexación (ello sin perjuicio de que, como hemos señalado anteriormente, este plazo finalmente se fija convencionalmente por la Administración por más que la ley pretenda lo contrario).

Tradicionalmente, la revisión de precios en los contratos de concesión se ha utilizado como una herramienta financiera que jugaba un papel esencial en la modelización de los planes económicos financieros de las concesiones, al establecer una curva de precios ascendente y progresiva, de manera que el precio iba gradualmente en aumento según avanzaba el plazo de la concesión, difiriendo la carga presupuestaria, en caso de que los pagos procedieran de la Administración, o el incremento de tarifa a los usuarios, en caso contrario, al final de la vida de la concesión.

Con el nuevo régimen de revisión de precios lo que ocurrirá es que las concesiones tendrán que afrontar una curva de precios prácticamente plana $\mathrm{y}$, al revés que hasta ahora, el esfuerzo presupuestario de la Administración o las tarifas a pagar por los usuarios será mayor al comienzo de la concesión.

Lo explicamos a continuación: 
- Para poder aprobar la fórmula de revisión, el Reglamento prevé un procedimiento determinado que pasa por elaborar y aprobar, en primer lugar, una estructura de costes de la actividad que se va a licitar y, una vez se obtiene dicha estructura, con base en ella, elaborar la fórmula de revisión incluyendo únicamente los costes revisables y el resto de límites impuestos por el Reglamento. No obstante, como el Reglamento de la Ley de Desindexación prevé la posibilidad de que la fórmula de revisión de precios sea una fórmula tipo aprobada por el Consejo de Ministros (inéditas hasta la fecha), en este caso el procedimiento para su inclusión en los pliegos se simplifica y se exige únicamente que el órgano de contratación justifique el periodo de recuperación de la inversión y por tanto el periodo en que se revisarán los precios del contrato.

- El art. 9.7 del Reglamento de Desindexación prevé el procedimiento y requisitos para obtener una estructura de costes adecuada en el que no nos vamos a detener pero que tiene una complejidad inusual por exigir consultas al mercado y un trámite de información pública.

- Una vez obtenida la estructura de costes de la concesión mediante el procedimiento citado, se procederá a fijar la fórmula de revisión de precios, que deberá respetar los principios siguientes: (i) no podrá ser modificada durante toda la vigencia del contrato, (ii) la fórmula de revisión de precios tan solo será aplicable cuando se haya ejecutado el $20 \%$ del importe del contrato y, además, hayan transcurrido dos años desde la formalización del contrato, (iii) la fórmula de revisión podrá incluir únicamente los costes de la actividad que, conforme a la estructura de costes realizada, cumplan con los arts. 3 y 4 del Reglamento, que se refieren respectivamente al principio de referenciación a costes y el principio de eficiencia y buena gestión empresarial. Por tanto, en línea con lo dispuesto en el art. 89.2 del TRLCSP, no podrán incluirse los costes asociados a: (i) amortizaciones; (ii) costes financieros; (ii) gastos generales o de estructura, ni (iv) beneficio industrial. Es decir, con el nuevo régimen, solo los costes revisables forman parte de la fórmula y únicamente en el porcentaje de su peso relativo en relación con la totalidad de costes del proyecto — según la estructura aprobada—. Por ello, bajo este nuevo régimen, quedan fuera de forma efectiva los costes financieros $y$, por tanto, la parte del precio que remunera dicho concepto. Pues bien, en los contratos de concesión la no inclusión en la revisión de los costes financieros tiene un impacto considerable y, además, en nuestra opinión, no termina de tener sentido. Indudablemente, los costes financieros que asume el concesionario sí varían durante la vida de la concesión —independientemente de que de forma privada las entidades y el concesionario otorguen habitualmente derivados que estabilicen los tipos de interés- 
y además suponen una parte muy importante del precio, puesto que la mayoría de concesiones tienen un ratio de apalancamiento elevado. Por ello, la exclusión expresa de la fórmula de revisión de este tipo de costes no parece que en concesiones pueda tener sentido, ya que, de no ser por la exclusión específica, los costes financieros reunirían todos los requisitos previstos en el Reglamento para poder ser revisados.

Por todo ello, la valoración general del nuevo régimen de revisión de precios en los contratos concesionales debe ser negativa y sería conveniente su reforma en profundidad. Introduce una complejidad exagerada en la estructuración de los contratos concesionales con consultas obligatorias al mercado de dudosa utilidad y, sobre todo, exige proyectar fórmulas de revisión de precios que al no alinearse al IPC generarán siempre un riesgo muy relevante para las dos partes (Administración y contratista) por lo imprevisible de su comportamiento. ¿Y realmente tiene sentido todo este esfuerzo regulatorio para reducir la inflación? ¿Son realmente unas pocas decenas de contratos concesionales relevantes en su afección al nivel de inflación de la economía española? No lo creo.

\section{REEQUILIBRIO ECONÓMICO FINANCIERO DEL CONTRATO}

El principio general de equilibrio económico financiero de los contratos se mantiene en la nueva ley inalterado y el actual art. 270,1 tiene el mismo tenor literal del antiguo 258,1: «El contrato de concesión de obras deberá mantener su equilibrio económico en los términos que fueron considerados para su adjudicación, teniendo en cuenta el interés general y el interés del Sin embargo, hay dos modificaciones de entidad a este régimen general realmente poco acertadas y que generan una enorme perplejidad por la inconsistencia de su tenor. Se trata sin duda de modificaciones diseñadas como reacción a varios de los problemas que han generado los concursos de varias de las concesiones de peaje de autopistas, las denominadas «radiales de Madrid» y otras más licitadas en las mismas fechas. Como suele ser habitual, también en este caso «hard case makes bad law».

a) El art. 270.2,b) ha incorporado la siguiente previsión: «En todo caso no existirá derecho al restablecimiento del equilibrio económico financiero por incumplimiento de las previsiones de la demanda recogidas en el estudio de la Administración o en el estudio que haya podido realizar el concesionario».

Esta primera modificación pudiera parecer a priori una aclaración del principio general de riesgo y ventura en las concesiones o, en terminología de la nueva ley, del riesgo operacional. Sin embargo, si se profundiza sobre ella se 
generan enormes perplejidades. El problema es que no hay contextualización normativa alguna de la norma. Es cierto que con carácter general el concesionario debe asumir (o beneficiarse de) la caída o subida de la demanda en una concesión. Lo que no es cierto - y la norma ignora - es que esto deba ocurrir independientemente de cuál sea la causa. Llevemos el argumento al extremo: la Administración decreta el corte de determinados accesos a una vía de peaje concesionada y, por ello, cae el $25 \%$ la demanda. Es claro que existe una causa que justifica la solicitud de un reequilibrio al amparo del principio del «factum principis», pero no en genérico sino como consecuencia de una caída de la demanda, pues, si la demanda no se afecta, no parece que en sí mismo el cierre de dicho acceso dé en todo caso derecho al reequilibrio. El Tribunal Supremo vino, en su sentencia de 16 de mayo de 2011, a declarar, por ejemplo, el derecho al reequilibrio en una concesión de autopista por la causa de que no se había podido construir otra vía que continuaba el trazado de la concesionada ${ }^{25}$. También en este caso se trata de una caída en la demanda. Desde luego no puede interpretarse que dicha sentencia del TS no hubiera recaído en idéntico sentido en el caso de que el actual 270.2,b) hubiera estado en vigor.

En resumen, el nuevo inciso de la ley no debería cambiar nada del significado del equilibrio económico-financiero en relación con el riesgo de demanda de una concesión, ahora bien, es confuso porque al no matizar en absoluto el alcance del riesgo de demanda puede parecer que prescribe de forma taxativa una prohibición del reequilibrio de una concesión en el caso de caídas en la demanda, lo que desde luego no es acorde a los principios y contexto de la regulación del contrato de concesión. Por supuesto, esta conclusión también permitiría concluir que una demanda adicional inducida por una decisión administrativa puede, también, generar el derecho de la Administración a un reequilibrio a la baja de los ingresos de la concesión por más que se concrete en un aumento de la demanda.

b) La ley ha incorporado en segundo lugar un número 4 en el art. 270 que regula de forma novedosa el supuesto del riesgo imprevisible vinculado al progreso de la técnica. La norma resultante debe ser objeto de dura crítica.

25 En la STS de 16-5-11 se estimó el recurso de la concesionaria de la Autopista AP41 Madrid-Toledo porque el Ministerio de Fomento desestimó (a raíz de una declaración de impacto ambiental negativa) la construcción de la autovía Toledo-Ciudad Real-Córdoba, que era la continuidad de la AP41 y la que justificaba para muchos potenciales usuarios su utilización. Sobre esta sentencia puede verse E. Arimany Lamoglia (2011), «El equilibrio económico financiero de la concesión de obra pública: a propósito de la sentencia del TS autopista Madrid-Toledo AP-41», Actualidad jurídica Uría Menéndez, 1, págs. 93-100. 
La nueva regulación establece efectos específicos en el equilibrio económico financiero del contrato en dos supuestos: (i) el caso de aprobación de una disposición general por Administración distinta a la concedente con posterioridad a la formalización del contrato como (ii) el caso de que el concesionario deba incorporar, por venir obligado a ello legal o contractualmente, a las obras o explotación de avances técnicos que la mejoren notoriamente y cuya disponibilidad en el mercado, de acuerdo con el estado de la técnica, se haya producido con posterioridad a la formalización del contrato.

Pues bien, en ambos escenarios la ley introduce un nuevo concepto que es el de "extraordinaria onerosidad del contrato" que se define como aquella situación en la que, como consecuencia de la concurrencia de cualquiera de los dos supuestos referidos, se incrementen los costes del contrato en al menos el 5\% del importe neto de la cifra de negocios de la concesión, en términos anuales, por el periodo que reste de la vida de la concesión. Nótese que la cifra de incremento del coste que define la situación de "extraordinaria onerosidad» puede ser muy alta, ya que se calcula el $5 \%$ del importe de la cifra de negocios (la facturación) y se aplica sobre los costes (lógicamente menores), es decir, puede que nos encontremos debajo de dichos umbrales y el impacto económico sobre la concesión de dichas medidas sea muy alto sin que se genere derecho a reequilibrio alguno. Cada concesión tiene una estructura de costes e ingresos distinta, pero no es descartable que, estando debajo del umbral de la extraordinaria onerosidad, nos encontremos con concesiones que para recuperar la inversión tengan periodos de márgenes altos de tal manera que la no compensación de una diferencia del 4\% en los costes genere una situación de pérdidas o inviabilidad de la compañía.

Pero lo más grave es el inciso final: "Cuando el contratista desistiera del contrato como consecuencia de lo establecido en este apartado la resolución no dará derecho a indemnización alguna para ninguna de las partes». Esta conclusión plantea el problema de la inversión realizada por el concesionario y su indemnización. No tiene ningún sentido que, como parece indicar su tenor literal, por ejemplo, en el año 10 de una concesión licitada a 30 años y con una inversión de 200 millones de euros, una nueva normativa en relación a medidas de seguridad en túneles (por ejemplo) exige una inversión de más de ese $5 \%$ citado anteriormente, la única alternativa para la concesionaria es renunciar al contrato sin recibir indemnización alguna.

Creemos que se trata de un error de la ley que debe ser corregido vía pliegos y también mediante una modificación de la norma legal. 


\section{FINANCIACIÓN PRIVADA DE LAS CONCESIONES}

Los arts. 271 a 276 de la Ley de contratos regula el régimen jurídico de la financiación privada de infraestructuras.

Las novedades en este punto han sido menores. En primer lugar, se ha introducido un inciso final en el art. 272,1 estableciendo un plazo de dos meses para que se produzca el silencio positivo en relación con la titulización de valores de concesionarias. La novedad introducida llama la atención por dos motivos: (i) salvo error por mi parte no se ha titulizado nunca en España la tarifa de una concesionaria de tal manera que introducir novedades sobre un artículo de uso inédito genera dudas razonables acerca del criterio del legislador y, sobre todo, (ii) cualquier operador jurídico que haya trabajado en el mercado de las emisiones de valores de deuda conoce sin duda que tener que esperar un plazo de dos meses en dichos mercados para poder emitir es imposible por la realidad intrínseca de cómo funcionan los mercados de deuda. No se entiende bien, por otro lado, que en las mucho más comunes emisiones de bonos, el art. 271,4 del nuevo TRLSCSP, manteniendo el texto de la antigua ley, prevea sencillamente que dicha emisión debe ser comunicada al órgano de contratación en el plazo máximo de un mes (por tanto no debe ser autorizada, lo que tiene todo el sentido, pues la toma de deuda de la concesionaria no debe ser autorizada en el caso de deuda bancaria, por ejemplo).

En relación con las garantías otorgadas por las concesionarias hay una segunda pequeña novedad en relación con el art. 275.3, b) que elimina, en el proceso de subasta en la ejecución de una concesión hipotecada, la mención a que antes de la resolución de la concesión debería intentarse un previo acuerdo con los acreedores hipotecarios para fijar la cuantía de la deuda. No parece una medida razonable. Se trata solo de abrir un periodo de negociación con los acreedores que, en todo caso, será necesario — lo diga o no la ley— desde la perspectiva práctica. Encontramos aquí un nuevo impacto del «caso radiales» en normas generales con resultados erróneos.

Por último, aunque no es una novedad de la nueva ley sino que se introdujo en la modificación de 2015 en la antigua ley, debe recordarse que el art. 273,3 de la nueva ley establece que la pignoración de los derechos de indemnización por terminación anticipada de concesiones (la usualmente denominada en el argot bancario, con notable imprecisión, RPA de la concesión), así como los derivados de aportaciones públicas, deben ser autorizados previamente por el órgano de contratación y publicarse en el $B O E$ o boletín oficial autonómico. 


\section{INDEMNIZACIÓN EN CASOS DE RESOLUCIÓN ANTICIPADA DEL CONTRATO}

El régimen jurídico de la indemnización por terminación anticipada de los contratos concesionales fue también modificado en profundidad en la reforma introducida a través de las disposiciones adicionales de la Ley 40/2015, de 1 de octubre, de Régimen Jurídico del Sector Público.

El texto de la nueva regulación que, en la práctica, está todavía inédita en su aplicación entre nosotros, dado que el régimen regulado no tiene lógicamente efectos retroactivos, se recoge en los arts. 280, 281 y 282 de la nueva $\mathrm{LCSP}^{26}$.

La principal novedad en relación con esta regulación es la que se plantea en el caso de resolución anticipada por causa imputable al concesionario (típicamente el caso del concurso de acreedores que lleva a liquidación de la concesión). La reforma de 2015, que incorpora la nueva ley sin modificaciones, diseña un sistema de indemnización basado en la obligación para la Administración de sacar a subasta la concesión pagando al concesionario como indemnización el valor obtenido en la subasta. El art. 282 que regula el tipo de la subasta es, pese a que ha sido objeto de bastante atención por los comentaristas de la reforma, bastante irrelevante, pues, al final, tal y como señala el art. 281,1: «La licitación se realizará mediante subasta al alza, siendo el único criterio de adjudicación el precio».

Para entender bien los efectos del procedimiento regulado deben tenerse en cuenta dos cuestiones: (i) la ley prevé que la concesión no se modifique y que se licite por el tiempo restante; así «el nuevo concesionario se subrogará en la posición del primitivo concesionario», lo que para una concesión que ha fracasado en su diseño o gestión parece una solución un poco extrema, pues ciertas modificaciones en la misma pueden ser muy aconsejables y licitar una concesión concursada en sus mismos términos, en todo caso, no es en absoluto obvio que deba ser siempre la solución, (ii) este sistema de indemni-

26 Sobre el particular puede verse B. Lozano Cutanda (2015), «Nuevo régimen de resolución de las concesiones de obras públicas y drástica reducción de la RPA del concesionario en el Proyecto de Ley de Régimen Jurídico del Sector Público», Análisis GA\&P, septiembre. P. Silván Ochoa (2015), «Liquidación de contratos de concesión de autopistas de peaje y responsabilidad patrimonial de la administración concedente», en M. A. Recuerda Girela (dir.), Problemas prácticos y actualidad del Derecho Administrativo. Anuario 2015; I. Calatayud Prats (2017), «Riesgo y efectos de la resolución por incumplimiento del contratista de las concesiones de obra y servicio público: la liquidación del contrato (RPA) y la indemnización de daños y perjuicios», Revista General de Derecho Administrativo, Iustel. 
zación por terminación anticipada es bastante habitual en otras jurisdicciones y siempre genera el problema de la especulación sobre el valor de la concesión en escenarios en los que una concesión viable a largo plazo, sin embargo, no lo es a la vista del mercado de deuda que debe financiarla y son muchas veces los financiadores y las limitaciones en la capacidad de ofrecer suficiente deuda los que generan los colapsos en las concesiones. Se trata, en conclusión, de una regulación poco matizada y que muy probablemente en el momento en que deba utilizarse genere más problemas que ventajas. 